\title{
CARACTERIZACIÓN DE MODELOS DE COMUNICACIÓN DIGITAL EN ORGANIZACIONES DEL TERCER SECTOR
}

\section{CHARACTERIZATION OF DIGITAL COMMUNICATION MODELS IN ORGANIZATIONS OF THE THIRD SECTOR}

\author{
Alicia Inés Zanfrillo \\ Facultad de Ciencias Económicas y Sociales de la \\ Universidad Nacional de Mar del Plata \\ Mar del Plata, Buenos Aires, República Argentina \\ alicia@mdp.edu.ar
}

\author{
María Antonia Artola \\ Facultad de Ciencias Económicas y Sociales de la \\ Universidad Nacional de Mar del Plata \\ Mar del Plata, Buenos Aires, República Argentina \\ martola@mdp.edu.ar
}

Fecha de recepción: 15/08/2018 - Fecha de aprobación: 01/11/2018

\section{RESUMEN}

Los cambios establecidos por la Carta de Ottawa en la conceptualización de la salud pública sustituyeron estrategias de prevención de riesgos por otras de promoción centradas en el desarrollo de competencias. Contribuir a una mejor calidad de vida de las personas bajo condiciones sociales, políticas y económicas favorables implica asegurar los medios necesarios para un mayor control sobre las decisiones de salud con participación intersectorial conformada por diversas organizaciones.

El objetivo del trabajo consiste en reconocer los modelos comunicativos en organizaciones vinculadas con la salud del Tercer Sector de la ciudad de Mar del Plata (República Argentina) en la actualidad. Sobre la población en estudio se adopta una metodología cuantitativa, descriptiva, que revela estrategias ancladas en la prevención, de carácter determinista, vertical, basadas en la difusión de contenidos y escasamente orientadas hacia la construcción colectiva de pautas de comportamiento que permitan concientizar sobre los factores contributivos al bienestar psico-bio-social.

PALABRAS CLAVE: Tercer Sector; Evaluación de la Tecnología; Comunicación para el Desarrollo; Difusión de Información.

\section{ABSTRACT}

The changes established by the Ottawa Charter in the conceptualization of public health replaced risk prevention strategies with other promotion strategies focused on the development of competencies. Contributing to a better quality of life for people under favorable social, political and economic conditions implies ensuring the necessary means for

\footnotetext{
"Visión de Futuro" Año 16, Volumen N²3 N¹, Enero - Junio 2019 - Pág. 198 - 219

URL de la Revista: http://revistacientifica.fce.unam.edu.ar/

URL del Documento: http://revistacientifica.fce.unam.edu.ar/index.php?option=com content\&view=article\&id=492\&ltemid=101

ISSN 1668 - 8708 - Versión en Línea

E-mail: revistacientifica@fce.unam.edu.ar
} 
greater control over health decisions with intersectoral participation made up of different organizations.

The objective of the work is to recognize the communicative models in organizations linked to the health of the Third Sector of the city of Mar del Plata (Argentine Republic) at present. A quantitative, descriptive methodology is adopted on the study population, revealing strategies anchored in prevention, deterministic, vertical, based on the dissemination of content and scarcely oriented towards the collective construction of behavioral patterns that allow awareness of the factors Contributory to psycho-bio-social well-being.

KEY WORDS: Third Sector; Technology Evaluation; Comunication for the Development; Dissemination of Information.

\section{INTRODUCCIÓN}

La profunda transformación generada por la incorporación de internet en todos los ámbitos del quehacer humano remite a un nuevo paradigma donde la información no constituye un producto acabado sino que fluye, líquida, en ambos sentidos desde una lógica horizontal o circular entre organizaciones y usuarios ofreciendo a estos últimos la oportunidad de enriquecerla o modificarla en forma permanente. Mientras que el uso de internet ha facilitado el acceso a la información como la eliminación de barreras espaciotemporales contribuyendo a la democratización del conocimiento, una revolución en las formas de hacer se genera por el cambio de rol de los usuarios de receptores pasivos a prosumidores o web-actores a través de las posibilidades de interacción y participación que proveen las herramientas de la web social (Pisani y Piotet, 2009).

En un contexto de desigualdades según zona y género entre otras brechas reconocidas en el acceso de los usuarios de las tecnologías de la información y de la comunicación (TIC) la nueva concepción de salud pública dispone de una amplia y diversa variedad de instrumentos tecnológicos en su misión de divulgar información, proporcionar formación y proveer al desarrollo de capacidades en las personas que les permitan disponer de los medios necesarios para adoptar las mejores decisiones en pos de su bienestar psicobio-social (OMS, 1986). Dado que el concepto de salud no se circunscribe únicamente a un estado físico sino que implica "... ser capaz de identificar y realizar sus aspiraciones, de satisfacer sus necesidades y de cambiar o adaptarse al medio ambiente" (OMS, 1986, p.1), su promoción requiere acciones articuladas con otros agentes y organizaciones donde las tecnologías actúen como interfaz para el desarrollo de las vinculaciones de estos grupos

\footnotetext{
"Visión de Futuro" Año 16, Volumen No 23 N¹, Enero - Junio 2019 - Pág. 198 - 219

URL de la Revista: http://revistacientifica.fce.unam.edu.ar/

URL del Documento: http://revistacientifica.fce.unam.edu.ar/index.php?option=com content\&view=article\&id=492\&ltemid=101

ISSN 1668 - 8708 - Versión en Línea

E-mail: revistacientifica@fce.unam.edu.ar
} 
atendiendo además a la necesidad de empoderamiento de los usuarios que supone adquirir un mayor control sobre su bienestar.

Profesionales, organizaciones, pacientes o público en general han hecho de internet su principal fuente de información en temas sobre salud accediendo a sitios para la búsqueda de contenidos y gestión de trámites en línea como a comunidades de práctica y espacios de interacción (Jiménez Pernett, García Gutiérrez, Martín Jiménez y BermúdezTamayo, 2007; Lima-Pereira, Bermúdez-Tamayo y Jasienska, 2012; Beck, Richard, NguyenThanh, Montagni, Parizot y Renahy, 2014). La disponibilidad de herramientas tecnológicas ha facilitado el desarrollo de un vasto número de sitios sobre salud con características de calidad diversa constituyendo una preocupación permanente que ha dado origen al desarrollo de instrumentos para evaluar la validez de sus contenidos y la responsabilidad sobre su autoría (Núñez Gudás, 2002; Mayer, Leis y Sanz, 2009; Marín-Torres, Aliaga, Miró, del Castillo Vicente, Polentinos-Castro y Barral, 2013; Villaescusa Martínez y Sáez Villar, 2013).

Sin embargo, estas revisiones indican que la importancia de la información no radica en las ventajas para su acceso o en las facilidades para su manipulación sino en el empleo posterior que se realice con ella tal como muestran los estudios sobre la influencia positiva del uso de internet sobre el comportamiento de los pacientes (Marín-Torres et al., 2013; Sacks, Hernando, Aguilar, Vega y Fernández, 2013). A fin de lograr una mayor autonomía y responsabilidad de los usuarios en el sistema sanitario de la nueva sociedad red se requieren diferentes tipos de alfabetizaciones relacionadas tanto con el acceso como con el uso de información biomédica que faciliten un mayor control sobre su bienestar (Jiménez Pernet et al., 2007; Lupiáñez-Villanueva, 2011). Estas competencias no se desarrollan únicamente con la disponibilidad tecnológica, sino que requieren de la disposición de espacios para la formación y la interacción a fin de adquirir conocimientos y aplicarlos en situaciones específicas.

Entre los estudios relacionados con internet en el sistema de salud se distinguen diferentes líneas de investigación que abordan los recursos tecnológicos y sus efectos en términos de información. Como las nuevas relaciones que se definen entre los actores, ofreciendo grandes posibilidades para la transformación de las prácticas sanitarias. Según Powell, Lowe, Griffiths y Thorogood (2005) se reconocen cinco áreas de investigación en la temática: calidad de la información sobre salud, uso de información sanitaria, efectos en la relación entre profesionales y pacientes a través de internet, comunidades virtuales y grupos de autoayuda y por último, prestación de servicios digitales. En la línea del uso de la información se encuentran referencias abundantes sobre búsquedas de temas específicos, competencias y efectos sobre su conocimiento en pacientes y público en general (Marín-

\footnotetext{
"Visión de Futuro" Año 16, Volumen N²3 N¹, Enero - Junio 2019 - Pág. 198 - 219

URL de la Revista: http://revistacientifica.fce.unam.edu.ar/

URL del Documento: http://revistacientifica.fce.unam.edu.ar/index.php?option=com content\&view=article\&id=492\&ltemid=101

ISSN 1668 - 8708 - Versión en Línea

E-mail: revistacientifica@fce.unam.edu.ar
} 
Torres et al., 2013; González Rivero, Santana Arroyo, 2008; Laugesen, Hassanein y Yuan, 2015, Solves, Santacreu, Martínez y Remón, 2009; Muñoz-Miralles, Ortega-González, Batalla-Martínez, López-Morón, Manresa y Torán-Monserrat, 2014), con escaso abordaje sobre las instituciones y las estrategias de comunicación elegidas en materia de prevención y promoción de la salud (Jones, Rudin, Perry y Shekelle, 2014).

Nuestra investigación se enfoca en determinar los modelos comunicativos que adoptan las organizaciones del sector salud de la ciudad de Mar del Plata de la República Argentina en el año 2017 a fin de empoderar a sus usuarios, esto es, facilitar los instrumentos que les permitan adoptar un mayor control sobre su bienestar a través de la selección de nuevas prácticas de comportamiento y participación social. La hipótesis del trabajo define a las organizaciones de la localidad asentadas en un modelo comunicativo difusionista basado en la prevención de la salud con escaso fomento del desarrollo de competencias en los usuarios. Para ello se identificaron tres variables: difusión de información, empoderamiento e integración comunitaria emergentes de la revisión de la literatura científica que caracterizan los modelos comunicativos. El relevamiento se efectúa a través del análisis de los contenidos publicados en los website corporativos para la prevención y promoción de la salud atendiendo especialmente a las campañas, herramientas de interacción y propuestas formativas dispuestas para la transimisión de conocimiento y la participación de los usuarios en plataformas y espacios de discusión.

La investigación se encuentra limitada en el alcance, pues si bien se aborda el total de organizaciones de la localidad vinculadas con los servicios de salud, se circunscribe a una ciudad de la República Argentina. Otra limitación radica en la adopción del website como principal fuente para el análisis de contenidos sin contemplar la pluralidad de opciones disponibles por considerar la presencia web de carácter estratégica y espacio para la integración de las herramientas de la web social. La importancia del estudio radica en determinar el modelo comunicativo definido en estas organizaciones y así contribuir a la formulación de políticas públicas que fomenten iniciativas no solo de validez de contenidos o de difusión de información sino que desarrollen el marco de participación y aprendizaje para que los usuarios puedan asumir un mayor control, responsable y de carácter participativo, sobre los temas sanitarios que le resultan de interés, así como en el desarrollo de competencias para la transformación de prácticas sanitarias de construcción colectiva.

\footnotetext{
"Visión de Futuro" Año 16, Volumen No 23 N¹, Enero - Junio 2019 - Pág. 198 - 219

URL de la Revista: http://revistacientifica.fce.unam.edu.ar/

URL del Documento: http://revistacientifica.fce.unam.edu.ar/index.php?option=com content\&view=article\&id=492\&Itemid=101

ISSN 1668 - 8708 - Versión en Línea

E-mail: revistacientifica@fce.unam.edu.ar
} 


\section{DESARROLLO}

\section{Revisión de literatura}

Equidad, solidaridad y universalidad son los principios constitutivos de los sistemas de salud. Representan el fundamento para la consecución de objetivos basados en una atención sanitaria integral, la concientización de las personas sobre pautas de comportamiento y hábitos saludables como la prevención de enfermedades y riesgos para toda la población. Sin embargo, una vasta historia se plantea detrás de esta definición bajo los términos de enfermedad, prevención, salud pública y más recientemente, promoción de la salud. El concepto de enfermedad se ha extendido en la historia de la humanidad desde una visión ambientalista fundada en la intrusión de agentes externos en los seres vivientes sosteniéndose esta perspectiva en el tiempo gracias a los avances tecnológicos ocurridos en medicina desde el Renacimiento hasta el siglo XX tales como el microscopio, el estetoscopio, los rayos $\mathrm{X}$, el rayo láser, las vacunas, la anestesia, las vitaminas y la penicilina entre otros (Carmona Moreno, Rozo Reyes y Mogollón Pérez, 2005). Estos avances facilitaron la continuidad del paradigma cartesiano en la separación entre las concepciones de cuerpo y mente, centrando en procesos fisiológicos e infecciones, heridas y desequilibrios químicos los causales de enfermedad sin considerar la incidencia de los procesos psicológicos y sociales (Martínez-Donate y Rubio, 1999).

Consecuencia de los importantes descubrimientos que mejoraron la nutrición y facilitaron la disminución de la mortalidad a través de la aplicación tanto de métodos de diagnóstico como tratamientos preventivos más eficaces, el escenario epidemiológico de los países industrializados ubicados tanto en Norte América como Europa ha sufrido profundas transformaciones. Durante los siglos XIX y mediados del XX se registra un cambio cualitativo sobre los causantes de fallecimiento gracias a los descubrimientos en farmacología y cirugía (Martínez-Donate y Rubio, 1999). Este cambio no solo genera una mayor expectativa de vida, sino que desplaza los causales de mortalidad desde las enfermedades infecciosas (transmisibles) y los trastornos de desnutrición hacia enfermedades relacionadas con el cáncer, afecciones coronarias, la falta de hábitos saludables, abuso de sustancias tóxicas y accidentes viales, es decir hacia las no infecciosas (no transmisibles) (OMS, 2015).

En vista de las limitaciones de los agentes externos como explicación de la ocurrencia de enfermedades, a partir del siglo pasado el foco de atención se traslada a fin de contemplar otros factores relevantes para la salud humana además de los biológicos, tales como ambientales y sociales. Este escenario favorece una nueva concepción definida en 1946 por la Organización Mundial de la Salud (OMS) vigente a partir de 1948 y presente en

\footnotetext{
"Visión de Futuro" Año 16, Volumen No 23 N¹, Enero - Junio 2019 - Pág. 198 - 219

URL de la Revista: http://revistacientifica.fce.unam.edu.ar/

URL del Documento: http://revistacientifica.fce.unam.edu.ar/index.php?option=com content\&view=article\&id=492\&ltemid=101

ISSN 1668 - 8708 - Versión en Línea

E-mail: revistacientifica@fce.unam.edu.ar
} 
el Preámbulo de su Constitución, concibiéndose como “... un estado de completo bienestar físico, mental y social, y no solamente la ausencia de afecciones o enfermedad" (OMS, 2014, p.1). Esta defnición no se encuentra exenta de críticas. Una de ellas se sustenta en la asunción de un consenso general en torno a los términos empleados en esta definición sin considerar el carácter de fenómeno social e histórico de la salud. Otras se enuncian a través de la naturaleza subjetiva del concepto de bienestar como en la utopía presente en su adjetivación refiriéndose a la cualidad de plenitud (Moreno, 2008).

Una nueva definición de salud tiene lugar desde una visión integral, entendida como un proceso bio-psico-social de carácter multidimensional en el cual los cambios que se producen entre los factores biológicos, psicológicos y sociales lleva al desplazamiento entre el bienestar psico-físico y la enfermedad según se altere el equilibrio entre las interacciones de dichos factores (Kornblit y Mendes Diz, 2000). Esta concepción adopta una perspectiva integral sobre la salud humana con énfasis en la instalación tanto de hábitos saludables como en el fomento de conductas para la resistencia de afecciones y alteraciones del bienestar de las personas. A diferencia del origen patogénico de la prevención de enfermedades procedente del movimiento higienista del siglo XX bajo el precepto que "... puede ser menos costoso y más efectivo impedir la aparición de los problemas que tratarlos cuando ya se han establecido" (Gómez y González, 2009, p. 89), la promoción de la salud tiene un origen reciente situado a mediados del siglo pasado, inspirado por las medidas precautorias frente a las epidemias y la mejora de las condiciones de trabajo. Desde una perspectiva participativa involucra diferentes agentes y organizaciones a fin de garantizar los factores que contribuyan al bienestar de la población definida como “... los medios necesarios para mejorar su salud y ejercer un mayor control sobre la misma" (OMS, 1986, p.1). Con un enfoque positivo, multisectorial e interdisciplinar en la configuración de los determinantes de la salud resulta más abarcativo que la restricción a la situación de afección o enfermedad sino que favorece el desarrollo de condiciones propicias en el ambiente y de comportamientos salubles en torno a buenas prácticas.

La promoción de la salud reconoce la importancia de "... considerar las circunstancias en que las personas nacen, crecen, viven, trabajan y envejecen, incluido el sistema de salud" (OMS, 2018, p.1), es decir aquellas condiciones que resultan determinantes para su estado de bienestar e inherentes al estilo de vida, a las prácticas de consumo y a las características tanto del entorno como de las organizaciones (Figueroa-Duarte y CampbellAraujo, 2014). Dado el tiempo de la vida de las personas que transcurre en el marco de las organizaciones, ya sea por su actividad laboral, profesional, académica o comunitaria, resulta un espacio de interés para llevar adelante políticas públicas que faciliten la promoción de la salud pues “...ya sean empresas, lugares de trabajo, universidades, 
escuelas, etc., constituyen el entorno más propicio para promover la adopción de un estilo de vida saludable que abarque y acompañe todo el ciclo de vida de la persona", definiéndose así nuevos espacios para el desarrollo de estas prácticas (Ministerio de Salud, 2018, p.1).

Eriksson y Lindstrom (2008) expresan el desarrollo de la salud pública desde la atención y el tratamiento hasta la prevención y promoción, es decir desde la perspectiva patogénica hasta la salutogénica reconociendo cuatro etapas: (i) la curación o tratamiento de enfermedades, (ii) la protección de la salud y prevención de enfermedades, (iii) educación y promoción de la salud y (iv) mejora de la percepción de la calidad de vida. En la tercera de estas etapas se proporcionan desde la educación recomendaciones sobre prácticas saludables a fin de evitar la exposición a situaciones de riesgo. Mientas que en la promoción se realizan acciones ccordinadas con diferentes agentes y organizaciones de la sociedad donde cada persona “... se convierte en un sujeto responsable, activo y participante. La tarea de los profesionales sería apoyar y ofrecer opciones para que las personas puedan tomar decisiones bien fundamentadas" (Rivera de los Santos, Ramos Valverde, Moreno Rodriguez y Garcia, 2011, p. 133). Se resalta así como objetivo de la promoción el desarrollo de aptitudes para la elección de las mejores alternativas en el bienestar de las personas.

Existen diferentes concepciones en la promoción de la salud, frecuentemente contrapuestas, como la que plantean Kornblit, Diz, Di Leo y Camarotti (2007) distinguiendo dos paradigmas, uno verticalista basado en la información con un rol pasivo para el sujeto y otro, de concepción democrática, con un rol activo en la construcción de conocimiento y el desarrollo de competencias. En esta línea de clasificación que reconoce el rol que desempeñan las personas en el control de sus acciones en la órbita de la salud se encuentran también las dos perspectivas señaladas por Gómez y González (2009), una acentuada en las capacidades individuales del sujeto y la otra basada en la integración de dimensiones para el desarrollo de políticas públicas. El enfoque individualista refuerza la responsabilidad del sujeto como su estilo de vida atendiendo a la difusión de información sobre factores de riesgo y el uso de servicios sanitarios para el cuidado personal mientras que el segundo enfoque se basa en una visión holística de los determinantes de salud. La integración de estas dos posturas considera a la promoción como una estrategia que vincula a las personas con su entorno atendiendo tanto a la autogestión como al resto de los determinantes de salud y la responsabilidad social.

Tres son los modelos que pueden identificarse en la promoción de la salud bajo una visión de complementariedad, no excluyentes entre sí, enfocados en el logro de objetivos

\footnotetext{
"Visión de Futuro" Año 16, Volumen No 23 N¹, Enero - Junio 2019 - Pág. 198 - 219

URL de la Revista: http://revistacientifica.fce.unam.edu.ar/

URL del Documento: http://revistacientifica.fce.unam.edu.ar/index.php?option=com content\&view=article\&id=492\&Itemid=101

ISSN 1668 - 8708 - Versión en Línea

E-mail: revistacientifica@fce.unam.edu.ar
} 
comunes y basados en el compromiso de las personas en la transformación de las prácticas (Kornblit y Diz, 2004; OMS, 1986) (Tabla 1):

- informativo, caracterizado por la difusión de contenidos referidos a creencias, actitudes y prácticas saludables,

- empoderamiento, representado por el desarrollo de competencias para la obtención de un mayor control sobre los determinantes de la salud,

- comunitario, caracterizado por distinguir la concepción de la salud como una construcción colectiva emergente del compromiso y la participación de las personas.

Con paralelismos reconocidos en el ámbito educativo según los modelos planteados por Kaplún (2002) y Palomares (2015), cada uno de estos estilos de promoción de la salud presenta fines específicos y se asocian con un modelo de comunicación. El modelo informativo, de carácter unidireccional, se caracteriza por el énfasis en los contenidos que se difunden a los públicos objetivos y el concepto de comunicación que subyace bajo este modelo es el de la 'comunicación bancaria' donde un emisor -uno de los actores del sistema de salud- envía su mensaje a los receptores -población destinataria- transfiriendo informaciones, ideas, sentimientos y capacidades a través de una diversidad de canales y formatos (Kaplún, 2002). En este modelo el destinatario adopta un rol pasivo: es el receptor de la información que el emisor, desde un papel protagónico y dominante, le ha presentado como acabada y completa, según su propia perspectiva. El receptor queda resignado únicamente a la decodificación del mensaje que el emisor como poseedor del saber legítimo ha propuesto para él (Spinelli, 2004).

Tabla №1. Modelos de promoción de la salud

\begin{tabular}{|l|l|l|l|l|}
\hline \multicolumn{1}{|c|}{ Modelo } & \multicolumn{1}{|c|}{ Propósito } & \multicolumn{1}{c|}{ Estilo } & \multicolumn{1}{c|}{ Característica } & \multicolumn{1}{c|}{ Rol del receptor } \\
\hline Informativo & $\begin{array}{l}\text { Recomendar } \\
\text { prácticas sanitarias }\end{array}$ & $\begin{array}{l}\text { Imperativo, } \\
\text { vertical, } \\
\text { unidireccional }\end{array}$ & $\begin{array}{l}\text { Transmisión de } \\
\text { información }\end{array}$ & Pasivo, silencioso \\
\hline $\begin{array}{l}\text { Empodera- } \\
\text { miento }\end{array}$ & $\begin{array}{l}\text { Desarrollar actitudes } \\
\text { y habilidades }\end{array}$ & $\begin{array}{l}\text { Pseudo- } \\
\text { bidireccional }\end{array}$ & $\begin{array}{l}\text { Énfasis en los } \\
\text { efectos }\end{array}$ & $\begin{array}{l}\text { Activo en los } \\
\text { espacios } \\
\text { determinados por el } \\
\text { emisor } \\
\text { (retroalimentación) }\end{array}$ \\
\hline Comunitario & $\begin{array}{l}\text { Promover la reflexión } \\
\text { y producción } \\
\text { colectiva de } \\
\text { prácticas sanitarias }\end{array}$ & Multi-direccional & $\begin{array}{l}\text { Desarrollo de } \\
\text { procesos } \\
\text { intersubjetivos }\end{array}$ & $\begin{array}{l}\text { Activon intervención } \\
\text { en todas las fases } \\
\text { del proceso } \\
\text { comunicativo }\end{array}$ \\
\hline
\end{tabular}

Fuente: Adaptado de Kornblit y Diz (2004)

El modelo de empoderamiento se caracteriza por condicionar al receptor para que adopte un nuevo comportamiento frente a las necesidades sanitarias planteando una retroalimentación entre ellos. Como nivel informativo, continúa siendo autoritario y vertical, en este caso motivando a las personas a adoptar nuevas conductas consideradas más

\footnotetext{
"Visión de Futuro" Año 16, Volumen No 23 N¹, Enero - Junio 2019 - Pág. 198 - 219

URL de la Revista: http://revistacientifica.fce.unam.edu.ar/

URL del Documento: http://revistacientifica.fce.unam.edu.ar/index.php?option=com content\&view=article\&id=492\&ltemid=101

ISSN 1668 - 8708 - Versión en Línea

E-mail: revistacientifica@fce.unam.edu.ar
} 
favorables en sustitución de antiguas prácticas a fin de lograr efectos determinados (Kaplún, 2002). La retroalimentación supone un instrumento que le permite al emisor confirmar el logro de sus objetivos que condiciona a los receptores para la emisión de respuestas preestablecidas. Sin embargo, su fin no se corresponde con lograr la participación de los usuarios y equilibrar así la asimetría existente en el rol protagónico desempeñado por emisor y receptor sino que pretende imponer conductas y comprobar los efectos previstos frente a las propuestas planteadas (Spinelli, 2004).

El modelo comunitario acentúa el diálogo y la interrelación entre los interlocutores privilegiando el carácter grupal, colectivo y horizontal a fin de transformar la realidad a través de la reflexión sobre la práctica (Kaplún, 2002). Este estilo comunicativo participativo rechaza las diferencias de jerarquías entre los roles que se establecen en la interacción de los sujetos sin prescindir de la información para abordar su análisis agregando la problematización a efectos de situar la reflexión sobre la práctica sanitaria. En este nivel la comunicación se establece como una relación de intercambio de mensajes en condiciones de reciprocidad alternando así los roles de emisor y receptor para cada sujeto (Spinelli, 2004). Sobre estos tres niveles otros autores distinguen dos concepciones, una centrada en la responsabilidad individual y otra, bajo la responsabilidad colectiva situando el nivel de empoderamiento en uno u otro nivel según el grado de autonomía que se dote al usuario en la selección de contenidos (Kornblit et al., 2007; Gumucio-Dagron, 2011).

En el ámbito sanitario con posterioridad a la primera década del nuevo siglo, surgen otras dos modelizaciones sobre los procesos comunicacionales: (i) el de Díaz (2011) que reconoce dos dimensiones, una informacional y otra relacional y (ii) el de Massoni, Mascotti y Margherit (2013) con la distinción de cuatro dimensiones: informativa, interaccional, ideológica y sociocultural. El modelo de Díaz (2011) propone un enfoque informacional, de carácter instrumental concebido como un proceso lineal entre emisor y receptor, se basa en la Teoría de la Información de principios de siglo pasado configurando una relación asimétrica entre el médico y el paciente, en la cual el primero es depositario del conocimiento. Dotando al momento de la emisión del mensaje como el de mayor importancia en el vínculo. Un segundo enfoque, relacional, ofrece una visión más amplia integrando la producción (emisor), circulación (canal) y el reconocimiento (receptor) bajo condiciones de tiempo y espacio que configuran el entorno de la relación, otorgando un rol activo al receptor como productor de sentido.

El modelo propuesto por Massoni et al. (2013) define una dimensión informativa que se centra en la transferencia de contenidos hacia los públicos de interés. La dimensión interaccional refiere al empoderamiento de los usuarios a partir de la interacción con otros agentes. La dimensión ideológica se relaciona con la sensibilización sobre los temas de

\footnotetext{
"Visión de Futuro" Año 16, Volumen No 23 N¹, Enero - Junio 2019 - Pág. 198 - 219

URL de la Revista: http://revistacientifica.fce.unam.edu.ar/

URL del Documento: http://revistacientifica.fce.unam.edu.ar/index.php?option=com content\&view=article\&id=492\&Itemid=101

ISSN 1668 - 8708 - Versión en Línea

E-mail: revistacientifica@fce.unam.edu.ar
} 
interés para la comunidad mientras que la dimensión sociocultural implica las acciones y sentidos que se realizan en el abordaje de problemáticas en un contexto en particular. Con diferencias reconocidas entre los modelos definidos anteriormente se observa una distinción básica entre aquellas acciones que se enmarcan en lineamientos prescriptivos bajo la forma de difusión de información y otros que ofrecen interacción con los usuarios. En el ámbito sanitario pueden reconocerse estas tipologías según el autor que se invoque para el análisis, ofreciendo en los modelos de mayor número de enfoques una apertura basada en la diversidad de actores y el tipo de respuesta definida en las estrategias de comunicación.

\section{Materiales y métodos}

La investigación adopta una metodología cuantitativa a fin de analizar las características de los modelos comunicativos en el ámbito digital empleados por las organizaciones que prestan servicios de salud en la ciudad de Mar del Plata en el año 2017 del sector privado, público y del Tercer Sector. La opción metodológica se basa en un estudio no experimental, de tipo descriptivo con enfoque principal cuantitativo, cuya recopilación de datos se realiza a partir de la distinción de las entidades activas en la ciudad que proporcionan servicios de salud efectuando un análisis de contenido sobre su website corporativo. La selección de unidades de análisis se basa en identificar entidades cuya misión se inscriba bajo la promoción del bienestar de las personas desde la concepción biopsico-social en la cual se aboga por un mayor control sobre los determinantes de la salud para los destinatarios de los servicios.

Bajo esta perspectiva, se consideran aquellas organizaciones que prestan y/o financian servicios de salud entre las que se consideran además las que proveen tratamientos terapeúticos, actividades recreativas o formativas para personas con discapacidad y aquellas que ofrecen estudios médicos exclusivos como exámenes genéticos. Se reconoce así para el estudio un amplio espectro de formas jurídicas inscriptas en la provisión de servicios sanitarios como asociaciones, fundaciones, mutuales y obras sociales con radicación de una sede en la localidad. La identificación de estas organizaciones se realizó a través de la búsqueda de entidades o filiales registradas en la Federación de Fundaciones Argentinas, la Confederación Argentina de Mutualidades, la Superintendencia de Servicios de Salud y el Instituto Nacional de Asociativismo y Economía Social. Estas entidades presentan un conjunto de atributos comunes para la conformación de la población bajo análisis:

- prestación de servicios de salud identificados a través de su actividad económica principal o secundaria constatada en el sistema de Administración Federal de

\footnotetext{
"Visión de Futuro" Año 16, Volumen No 23 N¹, Enero - Junio 2019 - Pág. 198 - 219

URL de la Revista: http://revistacientifica.fce.unam.edu.ar/

URL del Documento: http://revistacientifica.fce.unam.edu.ar/index.php?option=com content\&view=article\&id=492\&Itemid=101

ISSN 1668 - 8708 - Versión en Línea

E-mail: revistacientifica@fce.unam.edu.ar
} 
Ingresos (AFIP) y corroborada con los contenidos referidos a su misión, visión y objetivos presentes en el website corporativo,

- radicación en la ciudad de Mar del Plata, para la selección de entidades que ofrecen cobertura a nivel nacional se consideran aquellas que poseen domicilio en la ciudad para una de sus sedes sin contemplar empresas que actúen bajo un sistema capitado para la entidad original (pago prospectivo al prestador de los servicios de salud donde se asigna un valor monetario fijo por individuo y resulta independiente de la intensidad de la atención brindada),

- conformidad con las disposiciones tributarias nacionales determinada su regularidad en AFIP y en la Agencia de Recaudación de la Provincia de Buenos Aires (ARBA) a través de la identificación de personas físicas o jurídicas autónomas,

- $\quad$ presencia digital a través de un website corporativo.

Así las unidades de análisis se caracterizan por ser entidades prestadoras y/o financiadoras de servicios de salud inscriptas impositivamente en los organismos de control del Estado como AFIP y ARBA, que disponen de presencia digital para la comunicación de su quehacer con sus grupos de interés. Bajo estos criterios se identificaron 93 organizaciones del sector salud marplantense: 7 asociaciones, 2 fundaciones, 9 mutuales y 75 obras sociales. Se consideran financiadoras a las obras sociales y mutuales en tanto que entre las prestadoras se ubican las asociaciones y fundaciones. Las entidades pueden ejercer una u otra función o ambas a la vez, como es el caso de las obras sociales. De la comparación entre perspectivas de investigación se definen tres variables -difusión de información, empoderamiento e integración comunitaria- que contribuyen a caracterizar los modelos comunicativos presentes en cada entidad (Tabla 2). Éstas resultan de la comparación entre las investigaciones de Kornblit y Diz (2004), Díaz (2011), Massoni et al. (2013) y Palomares (2015) sobre las características y dimensiones de las estrategias comunicativas utilizadas. Se seleccionaron investigaciones que abordan la comunicación desde perspectivas multidimensionales a fin de generar un cambio en las conductas y comportamientos de los sujetos contemplando enfoques de tipo vertical centradas en el usuario y otras más democráticas sustentadas en la construcción colectiva (Kornblit et al., 2007; Lupton, 2014; Massoni et al., 2013).

Se establece la correspondencia entre los elementos teóricos y reales (Bostwick y Kyte, 2005) a través de un análisis de contenido manifiesto de corte cuantitativo para así obtener información sobre las variables en estudio. Entre los meses de junio y julio de 2017 se procedió a reconocer en cada website corporativo los valores correspondientes sobre difusión de información, empoderamiento e integración comunitaria presentes en las campañas de promoción y prevención de salud, así como en las plataformas que se ofrecen

\footnotetext{
"Visión de Futuro" Año 16, Volumen No 23 N¹, Enero - Junio 2019 - Pág. 198 - 219

URL de la Revista: http://revistacientifica.fce.unam.edu.ar/

URL del Documento: http://revistacientifica.fce.unam.edu.ar/index.php?option=com content\&view=article\&id=492\&ltemid=101

ISSN 1668 - 8708 - Versión en Línea

E-mail: revistacientifica@fce.unam.edu.ar
} 
en estos espacios a sus grupos de interés. Se determinó la presencia o ausencia de los diferentes elementos para cada indicador sin que resulten excluyentes las categorías propuestas. A partir de la identificación de los contenidos sobre prevención o promoción de la salud en el website, ya sea en la página principal o en espacios determinados para la difusión, se indica el tipo de valor correspondiente. Esta consigna se aplicó en una revisión completa de las propuestas informativas y recursos de interacción (plataformas, foros y cursos virtuales), sin restringirse a un único contenido o herramienta, sino al conjunto de elementos publicados a fin de determinar su disponibilidad para su empleo por los usuarios.

Tabla № 2. Resumen de variables e indicadores

\begin{tabular}{|l|l|l|l|l|}
\hline Variable & Dimensión & Descripción & Indicador & Valores \\
\hline \multirow{2}{*}{$\begin{array}{l}\text { Difusión de } \\
\text { información }\end{array}$} & $\begin{array}{l}\text { Contenido } \\
\text { específico }\end{array}$ & $\begin{array}{l}\text { Presencia de información sobre } \\
\text { prácticas sanitarias y preventivas } \\
\text { en internet sobre fomento de } \\
\text { prácticas sanitarias }\end{array}$ & $\begin{array}{l}\text { Existencia de } \\
\text { información }\end{array}$ & $\begin{array}{l}\text { Presencia } \\
\text { Ausencia }\end{array}$ \\
\cline { 2 - 5 } & $\begin{array}{l}\text { Formato de } \\
\text { difusión } \\
\text { de texposición del contenido en forma } \\
\text { (contenido externo, contenido de } \\
\text { elaboración propia y, actividades } \\
\text { tanto de protección como de } \\
\text { detección temprana de } \\
\text { cumplimiento obligatorio) }\end{array}$ & $\begin{array}{l}\text { Tipo de } \\
\text { contenido }\end{array}$ & $\begin{array}{l}\text { Noticias } \\
\text { Programas }\end{array}$ \\
\hline Empoderamiento & $\begin{array}{l}\text { Formación del usuario en } \\
\text { actividades y grupos donde se } \\
\text { comparten intereses comunes }\end{array}$ & $\begin{array}{l}\text { Plataformas } \\
\text { de formación }\end{array}$ & $\begin{array}{l}\text { Cursos virtuales } \\
\text { Ateneos }\end{array}$ \\
\hline \multirow{2}{*}{ Integración comunitaria } & $\begin{array}{l}\text { Formación del usuario en el } \\
\text { desarrollo de un pensamiento } \\
\text { crítico y participación fundada en } \\
\text { temas de interés }\end{array}$ & $\begin{array}{l}\text { Plataformas } \\
\text { de } \\
\text { construcción } \\
\text { colectiva }\end{array}$ & $\begin{array}{l}\text { Comunidad de } \\
\text { práctica } \\
\text { Foros de debate } \\
\text { y opinión }\end{array}$ \\
\hline
\end{tabular}

Fuente: Elaboración Propia

\section{Resultados}

Desde la perspectiva del financiamiento el sistema sanitario en la República Argentina se compone por tres sectores escasamente integrados: (i) el sector público en el que se encuentran ministerios tanto nacionales como provinciales además de hospitales y centros de salud, (ii) el sector del seguro social obligatorio organizado en torno a las obras sociales así como el Instituto Nacional de Servicios Sociales para Jubilados y Pensionados y (iii) el sector privado que incluye a los demandantes individuales (profesionales independientes y establecimientos) y a las entidades de seguro voluntario o sistemas de medicina prepaga incluyendo entre estas últimas a entidades como cooperativas y mutuales de salud (Belló y Becerril-Montekio, 2011). Según esta clasificación las entidades pertenecientes al Tercer Sector se incorporan al sector privado, sin embargo la importancia que revisten para la efectiva puesta en marcha de las acciones gubernamentales en el empoderamiento de los usuarios en materia sanitaria como establece la Carta de Ottawa (OMS, 1986) amerita su

\footnotetext{
"Visión de Futuro" Año 16, Volumen No 23 N¹, Enero - Junio 2019 - Pág. 198 - 219

URL de la Revista: http://revistacientifica.fce.unam.edu.ar/

URL del Documento: http://revistacientifica.fce.unam.edu.ar/index.php?option=com content\&view=article\&id=492\&ltemid=101

ISSN 1668 - 8708 - Versión en Línea

E-mail: revistacientifica@fce.unam.edu.ar
} 
diferenciación a fin de determinar los modelos comunicativos que utilizan y los medios digitales dispuestos para ello.

En la ciudad de Mar del Plata se identifican 93 organizaciones activas y con presencia digital pertenecientes al Tercer Sector vinculadas con los servicios de salud, distribuidas mayoritariamente entre obras sociales con un $80,6 \%$ y mutuales con el 9,7\%. La investigación empírica tiene como punto de partida el reconocimiento del tipo de estrategias digitales empleadas en la difusión de contenidos para la promoción del bienestar de la comunidad, entendida como el pilar sobre el que se asientan en forma complementaria los modelos de empoderamiento e integración comunitaria. Estas estrategias se manifiestan a través de enlaces a sitios de interés, noticias de elaboración propia, programas de prevención y campañas de promoción de la salud publicadas en diversos formatos y estilos. A fin de dar a conocer los contenidos sobre salud se emplearon diferentes medios como enlaces, imágenes, textos y videos abordándose una amplia variedad de temas. Sin embargo, esta diversidad temática y de formatos no tuvo su correspondencia con las herramientas de la web 2.0 que se utilizan escasamente para la difusión de contenidos específicos. Si bien en la actualidad se dispone de múltiples espacios digitales en los que se desarrolla actualmente el quehacer comunicativo de las organizaciones a fin de facilitar el acceso a usuarios no científicos a información sobre salud como los sitios web, las redes sociales, plataformas de aprendizaje y aplicaciones móviles (Lupton, 2014) no son ampliamente utilizados por el sector bajo análisis.

Bajo la pluralidad de herramientas y entornos de aprendizaje que abordan temas de salud sumado al incremento constante de usuarios de internet en nuestro país con el $70 \%$ de la población para 2017 en una variación de dos puntos porcentuales respecto del año anterior (ITU, 2017, 142) se observa un uso moderado en la variedad de formatos y tecnologías provistas para atender los requerimientos del sector. Esta situación resulta notoria para algunos tipos de entidades como las asociaciones y las mutuales que exhiben escasamente sus prácticas y prestaciones así como en el mínimo de recursos dispuestos para promover la participación de sus públicos de interés. El análisis revela una moderada difusión de información pues solamente el $58,1 \%$ de las entidades ofrecen contenidos específicos para la promoción del bienestar de la comunidad (Tabla 3).

Tabla № 3. Distribución de contenidos para la prevención y promoción de la salud según tipo de organización. Mar del Plata - 2017

\begin{tabular}{|l|c|c|c|c|c|}
\hline \multirow{2}{*}{\begin{tabular}{c}
\multirow{2}{*}{$\begin{array}{c}\text { Tipo de } \\
\text { organización }\end{array}$} \\
\cline { 2 - 6 }
\end{tabular}} & \multirow{2}{*}{ Total } & \multicolumn{4}{|c|}{ Contenidos específicos } \\
\cline { 2 - 6 } & & \multicolumn{2}{|c|}{ Con oferta } & \multicolumn{2}{c|}{ Sin oferta } \\
\hline Asociación & 7 & 2 & 28,6 & 5 & 71,4 \\
\hline Fundación & 2 & 2 & 100,0 & 0 & 0,0 \\
\hline Mutual & 9 & 2 & 22,2 & 7 & 77,8 \\
\hline
\end{tabular}

\footnotetext{
"Visión de Futuro" Año 16, Volumen No 23 N¹, Enero - Junio 2019 - Pág. 198 - 219

URL de la Revista: http://revistacientifica.fce.unam.edu.ar/

URL del Documento: http://revistacientifica.fce.unam.edu.ar/index.php?option=com content\&view=article\&id=492\&ltemid=101

ISSN 1668 - 8708 - Versión en Línea

E-mail: revistacientifica@fce.unam.edu.ar
} 


\begin{tabular}{|l|c|c|c|c|c|}
\hline Obra Social & 75 & 48 & 64,0 & 29 & 36,0 \\
\hline Total general & 93 & 54 & 58,1 & 39 & 41,9 \\
\hline
\end{tabular}

Fuente: Elaboración Propia

Mientras que las obras sociales publican estos contenidos aproximadamente en un número cercano a las dos terceras partes del total otro tipo de entidades, como las mutuales y asociaciones, son las que tienen la menor representación en el proceso de divulgación. En la categoría de fundaciones se encuentran presentes en ambas entidades contenidos pertinentes para llevar su mensaje a la comunidad. Un nutrido grupo de organizaciones del Tercer Sector, con presencia en internet, centran la divulgación de su quehacer en el ámbito digital en brindar información referida tanto a la imagen institucional como a las prestaciones médicas sin atender temáticas tendientes a facilitar un mayor control sanitario por parte de los usuarios. Para estas organizaciones la presencia en internet se adopta desde una visión determinística basada en la eficiencia administrativa sin contemplar el potencial transformador en el uso de las tecnologías a fin de empoderar o integrar a los usuarios a espacios de debate y construcción colectiva.

El formato básico de difusión de contenidos está representado básicamente por contenidos de replicación de campañas de otras reparticiones y enlaces a sitios con información médica encontrándose mayoritariamente a las mutuales, en segundo lugar las asociaciones y en menor medida las obras sociales (Tabla 4). La información sobre temas de interés sanitario como cuidados del recién nacido, nutrición balanceada, manejo responsable y primeros auxilios tiene una escasa presencia en todas las entidades, donde los artículos son redactados por personal de la institución. Si bien la mitad de las entidades que ofrece contenidos sobre prevención lo realiza bajo el formato de campañas es en las obras sociales donde tienen mayor relevancia con el 54,2\% observándose una mínima presencia en las mutuales y ausentes en el resto de las entidades. Los programas tienen presencia en las asociaciones y fundaciones quedando en segundo lugar con el $35,4 \%$ en las obras sociales donde se presentan contenidos locales, efemérides y una demanda inducida para el cumplimiento de actividades preventivas.

Tabla № 4. Distribución de contenidos para la prevención y promoción de la salud según tipo de organización. Mar del Plata - 2017

\begin{tabular}{|c|c|c|c|c|c|c|c|}
\hline \multirow{3}{*}{$\begin{array}{c}\text { Tipo de } \\
\text { organización }\end{array}$} & \multirow{3}{*}{$\begin{array}{c}\text { Total } \\
\mathrm{N}^{\circ}\end{array}$} & \multicolumn{6}{|c|}{ Contenidos específicos } \\
\hline & & \multicolumn{2}{|c|}{ Campañas } & \multicolumn{2}{|c|}{ Noticias } & \multicolumn{2}{|c|}{ Programas } \\
\hline & & $\mathrm{N}^{\circ}$ & $\%$ & $\mathrm{~N}^{\circ}$ & $\%$ & $\mathrm{~N}^{\circ}$ & $\%$ \\
\hline Asociación & 2 & 0 & 0,0 & 1 & 50,0 & 1 & 50,0 \\
\hline Fundación & 2 & 0 & 0,0 & 1 & 50,0 & 1 & 50,0 \\
\hline Mutual & 2 & 1 & 50,0 & 1 & 50,0 & 0 & 0,0 \\
\hline Obra Social & 48 & 26 & 54,2 & 5 & 10,4 & 17 & 35,4 \\
\hline Total general & 54 & 27 & 50,0 & 8 & 14,8 & 19 & 35,2 \\
\hline
\end{tabular}

Fuente: Elaboración Propia

\footnotetext{
"Visión de Futuro" Año 16, Volumen No 23 N¹, Enero - Junio 2019 - Pág. 198 - 219

URL de la Revista: http://revistacientifica.fce.unam.edu.ar/

URL del Documento: http://revistacientifica.fce.unam.edu.ar/index.php?option=com content\&view=article\&id=492\&Itemid=101

ISSN 1668 - 8708 - Versión en Línea

E-mail: revistacientifica@fce.unam.edu.ar
} 
La influencia de los recursos de internet sobre los medios de comunicación empleados por las entidades del Tercer Sector para la difusión de su quehacer resulta fácilmente observable en las obras sociales pues en su gran mayoría ofrecen contenidos a sus usuarios motivados por los cambios producidos por el potencial de las nuevas tecnologías. En los cuidados de la salud su empleo se visualiza a través de la digitalización de folletos o afiches que representan campañas preventivas, documentación anexa sobre enfermedades y tratamientos junto con otros recursos como revistas digitales y contenidos multimedia. Sin embargo, a pesar de la diversidad y sofisticación que ofrecen en la actualidad las redes sociales y las plataformas tecnológicas el rol que se asigna a los usuarios es el que corresponde a la web 1.0, donde el 'contenido es el rey' (Oller, Segarra y Plaza, 2012). Otra forma de visualizar la adopción de nuevas tecnologías es a través de la disposición de herramientas que faciliten la autogestión como la descarga de formularios en línea, la guía de trámites o la descarga de aplicaciones en sus dispositivos móviles para la gestión de turnos o para la formación sobre primeros auxilios y prevención de riesgo cardiovascular en sus dispositivos móviles.

A pesar de la sofisticación de las herramientas el nivel de intervención del usuario resulta escaso manteniendo los propósitos en eficiencia de la gestión administrativa y en la difusión de estrategias de prevención para la salud. En el estudio del empoderamiento los roles activos que se ejercen en espacios de formación y opinión como foros y sistemas de aprendizaje se ven reducidos en forma notoria y únicamente resulta visible en un reducido número de organizaciones asociativas de la localidad el empleo de blogs y canales en redes sociales que se utilizan para la transmisión de información. Si bien el pasaje a la web 2.0 se realiza desde las estrategias unidireccionales de comunicación hacia las bidireccionales, con el usuario como protagonista en la interacción con la organización (Pisani y Piotet, 2009; Oller, Segarra y Plaza, 2012) no se constata la existencia de herramientas que propicien el intercambio entre la organización y sus usuarios. Si bien se ofrecen conferencias y reuniones así como material de formación en formato digital, son escasamente aprovechadas, preferentemente como vehículo de difusión manteniendo una escasa o nula participación de los usuarios en ellos.

En el nivel de empoderamiento se puede destacar la disposición de ateneos a través de canales de redes sociales como Youtube que presentan casos de análisis a la comunidad científica con la intervención de diferentes profesionales del país a fin de ser accedidos por los usuarios en forma abierta. También existen propuestas formativas, algunas oficializadas a través de la Superintendencia de Servicios de Salud enmarcadas en estrategias de prevención como el cáncer de mama, diabetes e hipertensión arterial entre

\footnotetext{
"Visión de Futuro" Año 16, Volumen No 23 N¹, Enero - Junio 2019 - Pág. 198 - 219

URL de la Revista: http://revistacientifica.fce.unam.edu.ar/

URL del Documento: http://revistacientifica.fce.unam.edu.ar/index.php?option=com content\&view=article\&id=492\&ltemid=101

ISSN 1668 - 8708 - Versión en Línea

E-mail: revistacientifica@fce.unam.edu.ar
} 
otros. En este último caso se ofrecen cuadernillos e información en diversos formatos sobre el tema tratado los cuales se crean específicamente para la propuesta formativa. En la categoría de integración comunitaria no se advierten espacios destinados a conformar comunidades o foros con intervención de los usuarios que pudieran constituir una primera aproximación para la construcción de conocimiento, la reflexión desde la práctica y la incorporación del acervo cultural local en el diseño y difusión de contenidos.

En la comunicación con sus grupos de interés las entidades se inclinan asignar un rol preferentemente pasivo o con un estilo que incorpora herramientas y actores para ofrecer pautas y guías de comportamiento para una vida saludable o como espacio formativo y de debate. De los tres modelos teóricos definidos como informativo, empoderamiento y de integración comunitaria la investigación empírica sitúa a las organizaciones recorriendo principalmente el primero de los modelos enunciados con escasas manifestaciones en los modelos siguientes. Mientras que la mayoría de las entidades del Tercer Sector vinculadas con la salud en la localidad adopta un modelo difusionista principalmente a través de la replicación de afiches correspondientes a las campañas de orden provincial y nacional en forma puntual comienzan a identificarse otras que incorporan herramientas y contenidos que dan cuenta de su interés de proporcionar al usuario un rol más activo en el control de su bienestar. Las entidades que participan del modelo de difusión de información son mayoritariamente las obras sociales y las mutuales en su totalidad. Los indicios sobre el modelo de empoderamiento se concentran exclusivamente en las obras sociales y fundaciones mientras que el modelo de integración comunitaria se encuentra ausente en el análisis.

\section{CONCLUSIÓN}

El estudio empírico realizado se sitúa en la línea de investigación sobre el uso de información sanitaria atendiendo a tres consideraciones singulares: la primera, que se aborda población, es decir el conjunto de todas las organizaciones del Tercer Sector marplatenses, activas y con presencia digital a diferencia de otras investigaciones sustentadas en muestreo. La segunda se basa en la diversidad de la naturaleza jurídica y la amplitud en las prestaciones de salud ofrecidas por estas entidades bajo el sistema sanitario propio de la República Argentina, de difícil comparación con otros países. Por último, el análisis del empoderamiento de los usuarios a través de los procesos comunicativos definidos para la interacción con sus grupos de interés. Se observa a internet como fuente de información empleada por las entidades para su presencia corporativa, difusión de prestaciones y replicación de contenidos específicos para la prevención de la salud dotando al público lego de una vía de acceso a una vasta información médica con escaso desarrollo

\footnotetext{
"Visión de Futuro" Año 16, Volumen No 23 N¹, Enero - Junio 2019 - Pág. 198 - 219

URL de la Revista: http://revistacientifica.fce.unam.edu.ar/

URL del Documento: http://revistacientifica.fce.unam.edu.ar/index.php?option=com content\&view=article\&id=492\&ltemid=101

ISSN 1668 - 8708 - Versión en Línea

E-mail: revistacientifica@fce.unam.edu.ar
} 
de capacidades en los usuarios tal como se concibiera en los fundamentos de la articulación entre el Estado y las organizaciones del sector en la Carta de Ottawa.

La investigación empírica ha posibilitado corroborar la hipótesis inicial sobre el modelo de comunicación utilizado en las organizaciones del Tercer Sector vinculadas con la prestación y/o financiación de servicios de salud de la localidad constituido en torno a la difusión de contenidos, de tipo vertical e imperativo, con escaso empleo de herramientas de la web social. Las estrategias empleadas en la comunicación de su quehacer y que pueden facilitar el empoderamiento de los usuarios se centran en dos ejes, con una clara preponderancia del primero de ellos:

- difusión de campañas principalmente de origen nacional a través de la replicación de contenidos que son publicados como imágenes (afiches) para su visualización en el website,

- sensibilización de la ciudadanía a través de la publicación en el sitio web de efemérides, artículos de opinión y programas de prevención con directrices para su cumplimiento e inducción de la demanda.

El modelo principal que se distingue en el ámbito digital para estas entidades es del tipo informativo, vertical, prescriptivo sobre la conducta de los usuarios asignándoles un rol pasivo. El formato establecido para la difusión de contenidos se centra en la réplica de campañas de otras jurisdicciones con escasa incorporación de estrategias formativas a través de herramientas de interacción o bajo modalidades con mayor intervención de los usuarios como los canales de video o los ateneos virtuales respectivamente. Frente a la creciente atención recibida por las plataformas de la web 2.0 y las aplicaciones de redes sociales sustentadas en la actualidad por la proliferación de dispositivos móviles el empleo de estas herramientas por el sector aún se encuentra latente.

Se observa que las entidades que emplean modelos más tradicionales son mayoritariamente las mutuales y en segundo lugar las obras sociales aunque proporcionan medios para la promoción de la salud con contenidos locales. En el otro extremo, entre las más innovadoras en proveer medios para el empoderamiento de los usuarios se encuentran las asociaciones, las fundaciones y en menor medida las obras sociales. La escasa incorporación de un rol crítico da la pauta para considerar en este aspecto a las organizaciones de carácter asociativo de la localidad bajo el modelo de la web 1.0 con una incipiente aplicación de las herramientas de los social media pero bajo un modelo difusionista que le niega interacción a sus asociados y ralentiza las posibilidades formativas que puedan desarrollarse bajo las diferentes formas comunicativas mediadas por las tecnologías.

\footnotetext{
"Visión de Futuro" Año 16, Volumen No 23 N¹, Enero - Junio 2019 - Pág. 198 - 219

URL de la Revista: http://revistacientifica.fce.unam.edu.ar/

URL del Documento: http://revistacientifica.fce.unam.edu.ar/index.php?option=com content\&view=article\&id=492\&Itemid=101

ISSN 1668 - 8708 - Versión en Línea

E-mail: revistacientifica@fce.unam.edu.ar
} 
Tal como es la distinción entre la web 1.0 y la 2.0 el perfil de usuarios al que se dirigen estas organizaciones no le permite auto gestionar responsablemente sus prácticas y lo sitúa en una posición estática, sin posibilidad de interacción o conocimiento de otros grupos sociales con intereses similares. Resulta esencial proporcionar los medios para que, a lo largo de su vida, la población se prepare para adoptar una posición de mayor conocimiento frente a enfermedades y lesiones crónicas. A través del amplio tipo de organizaciones que pueden articular con el Estado se puede contribuir al cumplimiento de este objetivo, a fin de favorecer el desarrollo personal y social proporcionando información y educación sanitaria en una clara intención de desarrollo de las aptitudes indispensables para una vida saludable.

\section{REFERENCIAS}

Beck, F., Richard, J. B., Nguyen-Thanh, V., Montagni, I., Parizot, I. \& Renahy, E. (2014). Use of the Internet as a Health Information Resource among French Young Adults: Results from a Nationally Representative Survey. Journal of Medical Internet Research, 16(5), $128 . \quad$ Recuperado de https://www.ncbi.nlm.nih.gov/pmc/articles/PMC4051740/

Belló, M. \& Becerril-Montekio, V. M. (2011). Sistema de salud de Argentina. Salud pública de México, 53(2), S96-S108. Recuperado de http://www.scielo.org.mx/scielo.php?pid=S0036$36342011000800006 \&$ script=sci arttext\&tlng=en

Bostwick, G., \& Kyte, N. (2005). Social Work: Research and Evaluation. Quantitive and Qualitative Approaches. (7 ed.). New York, EEUU: Oxford University Press.

Carmona Moreno, L. D., Rozo Reyes, C. M. \& Mogollón Pérez, A. S. (2005). La salud y la promoción de la salud: una aproximación a su desarrollo histórico y social. Revista ciencias de la Salud, 3(1), 62-77. Recuperado de http://www.redalyc.org/pdf/562/56230108.pdf

Díaz, H. A. (2011). La comunicación para la salud desde una perspectiva relacional. En U. Cuesta, T. Menéndez y A. Ugarte (Coords.), Comunicación y salud: nuevos escenarios y tendencias (pp. 33-44). Madrid, España: Complutense. Recuperado de http://biblioteca.ucm.es/ecsa/9788499380889.pdf\#page=34

Eriksson, M. \& Lindstrom, B. (2008). A Salutogenic Interpretation on the Ottawa Charter. Health Promot international, 23, 190-98.

Figueroa-Duarte, A. S. \& Campbell-Araujo, O. A. (2014). Determinantes Sociales de la Salud; su Relevancia en el Abordaje de los Problemas de Salud Mental Infantil. EI Caso del TDAH. Boletín Clínico del Hospital Infantil del Estado de Sonora, 31(2), 66-

\footnotetext{
"Visión de Futuro" Año 16, Volumen No 23 N¹, Enero - Junio 2019 - Pág. 198 - 219

URL de la Revista: http://revistacientifica.fce.unam.edu.ar/

URL del Documento: http://revistacientifica.fce.unam.edu.ar/index.php?option=com content\&view=article\&id=492\&ltemid=101 
76. Recuperado de http://www.medigraphic.com/pdfs/bolclinhosinfson/bis2014/bis142b.pdf

Goméz, R. \& González, E. (2009). Evaluación de la prevención de la enfermedad y la promoción de la salud: factores que deben considerarse. Revista Facultad Nacional de Salud Pública, 22(1), 87-106. Recuperado de http://aprendeenlinea.udea.edu.co/revistas/index.php/fnsp/article/view/711/615

González Rivero, M. D. C. \& Santana Arroyo, S. (2008). Comportamiento de los estudiantes de medicina en la búsqueda de información en Internet. Acimed, 17(4), 1-7. Recuperado de http://scielo.sld.cu/pdf/aci/v17n4/aci09408.pdf

Gumucio-Dagron, A. (2011). Comunicación para el cambio social: clave del desarrollo participativo. Signo y pensamiento, 30 (58), 26-39. Recuperado de http://www.redalyc.org/html/860/86020038002/

Jiménez Pernett, J., García Gutiérrez, J. F., Martín Jiménez, J. L. \& Bermúdez Tamayo, C. (2007). Tendencias en el uso de Internet como fuente de información sobre salud. UOC Papers: Revista sobre la sociedad del conocimiento, (4), 44-50. Recuperado de http://www.redalyc.org/html/790/79000411/

Jones, S. S., Rudin, R. S., Perry, T., \& Shekelle, P. G. (2014). Health Information Technology. An Updated Systematic Review with a Focus on Meaningful Use. Annals of Internal Medicine, 160(1), 48-54. Recuperado de http://annals.org/aim/fullarticle/1811028

Kaplún, M. (2002). Una Pedagogía de la comunicación (el comunicador popular). La Habana, Cuba: Caminos.

Kornblit, A. L. \& Diz, A. M. M. (2004). Teoría y práctica en promoción de la salud: el caso del consumo abusivo de drogas. En A. L. Kornblit (Coord.), Nuevos estudios sobre drogadicción. Consumo e identidad (pp. 11-120). Buenos Aires, Argentina: Biblos.

Kornblit, A. L. \& Diz, A. M. M. (2000). La salud y la enfermedad: aspectos biológicos y sociales. Buenos Aires: Aique.

Kornblit, A. L., Diz, A. M. M., Di Leo, P. F. \& Camarotti, A. C. (2007). Entre la teoría y la práctica: algunas reflexiones en torno al sujeto en el campo de la promoción de la salud. Revista Argentina de Sociología, 5(8), 11-27. Recuperado de http://www.scielo.org.ar/scielo.php?pid=S1669$32482007000100002 \&$ script $=$ sci arttext\&tlng=en

Laugesen, J., Hassanein, K. \& Yuan, Y. (2015). The Impact of Internet Health Information on Patient Compliance: a Research Model and an Empirical Study. Journal of Medical Internet Research, 17(6), 143. Recuperado de https://www.ncbi.nlm.nih.gov/pmc/articles/PMC4526934/

\footnotetext{
"Visión de Futuro" Año 16, Volumen No 23 N¹, Enero - Junio 2019 - Pág. 198 - 219

URL de la Revista: http://revistacientifica.fce.unam.edu.ar/

URL del Documento: http://revistacientifica.fce.unam.edu.ar/index.php?option=com content\&view=article\&id=492\&ltemid=101 
Lima-Pereira, P., Bermúdez-Tamayo, C. \& Jasienska, G. (2012). Use of the Internet as a Source of Health Information Amongst Participants of Antenatal Classes. Journal of Clinical Nursing, 21(3-4), 322-330. Recuperado de http://onlinelibrary.wiley.com/doi/10.1111/j.1365-2702.2011.03910.x/full

Lupiáñez-Villanueva, F. (2011). Salud e internet: más allá de la calidad de la información. Revista Española de Cardiología, 64(10), 849-850. Recuperado de http://www.revespcardiol.org/es/content/articulo/90027202/

Lupton, D. (2014). Health Pin the Digital Era: a Critical Commentary. Health promotion international, 30(1), 174-183.

Recuperado

de https://academic.oup.com/heapro/article-abstract/30/1/174/2805780

Marin-Torres, V., Aliaga, J. V., Miró, I. S., Del Castillo Vicente, M. I. S., Polentinos-Castro, E. \& Barral, A. G. (2013). Internet como fuente de información sobre salud en pacientes de atención primaria y su influencia en la relación médico-paciente. Atención Primaria, 45(1), 46-53.

Recuperado

de https://www.sciencedirect.com/science/article/pii/S0212656712003782

Martínez-Donate, A. \& Rubio, V. J. (1999). Enfoque biopsicosocial de la salud. Madrid, España: Universidad Autónoma de Madrid. Recuperado de http://www.uam.es/ personal pdi/psicologia/victor/SALUD/

Massoni, S., Mascotti, M. \& Margherit, L. (2013). Medición de procesos comunicacionales en organizaciones y proyectos: la dimensión informativa desde la comunicación estratégica. Razón y palabra, 18(85). Recuperado de http://www.redalyc.org/html/1995/199531506045/

Mayer, M. Á., Leis, Á. \& Sanz, F. (2009). Información sobre salud en internet y sellos de confianza como indicadores de calidad: el caso de las vacunas. Atención primaria, 41(10), 534-542. Recuperado de: https://www.sciencedirect.com/science/article/pii/S021265670900184X

Ministerio de Salud (2018). Entornos saludables. Buenos Aires, Argentina: Ministerio de Salud. Recuperado de http://www.msal.gob.ar/ent/index.php/informacion-paraciudadanos/entornos-saludables

Moreno, G. A. (2008). La definición de salud de la Organización Mundial de la Salud y la interdisciplinariedad. Sapiens: Revista Universitaria de Investigación, 9(1), 93-107. Recuperado de https://dialnet.unirioja.es/descarga/articulo/2781925.pdf

Muñoz-Miralles, R., Ortega-González, R., Batalla-Martínez, C., López-Morón, M. R., Manresa, J. M. \& Torán-Monserrat, P. (2014). Acceso y uso de nuevas tecnologías entre los jóvenes de educación secundaria, implicaciones en salud. Atención

\footnotetext{
"Visión de Futuro" Año 16, Volumen No 23 N¹, Enero - Junio 2019 - Pág. 198 - 219

URL de la Revista: http://revistacientifica.fce.unam.edu.ar/

URL del Documento: http://revistacientifica.fce.unam.edu.ar/index.php?option=com content\&view=article\&id=492\&ltemid=101

ISSN 1668 - 8708 - Versión en Línea

E-mail: revistacientifica@fce.unam.edu.ar
} 
Primaria, 46(2),

77-88.

Recuperado

de

https://www.sciencedirect.com/science/article/pii/S021265671300187X

Núñez Gudás, M. (2002). Criterios para la evaluación de la calidad de las fuentes de información sobre salud en Internet. Acimed, 10(5), 9-10. Recuperado de http://scielo.sld.cu/scielo.php?script=sci arttext\&pid=S1024-94352002000500005

Oller Alonso, M.; Segarra Saavedra, J. \& Plaza Nogueira, A. (2012). La presencia de las revistas científicas de Ciencias Sociales en los 'Social Media': de la Web 1.0 a la Web 2.0. Index.comunicación, (2), 49-68. Recuperado de http://journals.sfu.ca/indexcomunicacion/index.php/indexcomunicacion/article/view/27 132

Organización Mundial de la Salud (2018). Determinantes sociales de la salud. Ginebra, Suiza: OMS. Recuperado de http://www.who.int/social_determinants/es/

Organización Mundial de la Salud (2015). Informe mundial sobre el envejecimiento y la salud. Ginebra, Suiza: OMS. Recuperado de http://apps.who.int/iris/bitstream/10665/186466/1/9789240694873 spa.pdf.

Organización Mundial de la Salud (2014). Documentos Básicos (48 ed.). Italia: OMS.

Recuperado de http://apps.who.int/gb/bd/PDF/bd48/basic-documents-48th-editionsp.pdf?ua=1\#page $=7$

Organización Mundial de la Salud (1986). The Ottawa Charter for Health Promotion. Ginebra, Suiza: OMS. Recuperado de http://www.who.int/healthpromotion/conferences/previous/ottawa/en/index4.html

Palomares, A. (2015). Análisis de modelos de comunicación, profesorado-familia, para gestionar conflictos. Estudio de la comunidad educativa de Albacete. Pedagogía Social: Revista Interuniversitaria, (25), 277-298. Recuperado de http://www.redalyc.org/html/1350/135043709012/

Pisani, F. \& Piotet, D. (2009): La alquimia de las multitudes. Cómo la web esta cambiando el mundo. Madrid, España: Paidos Comunicación.

Powell, J. A., Lowe, P., Griffiths, F. E. \& Thorogood, M. (2005). A Critical Analysis of the Literature on the Internet and Consumer Health Information. Journal of Telemedicine and Telecare, 11(1_suppl), 41-43. Recuperado de http://journals.sagepub.com/doi/abs/10.1258/1357633054461642

Rivera De Los Santos, F.; Ramos Valverde, P.; Moreno Rodriguez, C. y Hernan Garcia, M. (2011). Análisis del modelo salutogénico en España: aplicación en salud pública e implicaciones para el modelo de activos en salud. Revista Española de Salud Pública, $85(2)$, 129-139.

Recuperado de

\footnotetext{
"Visión de Futuro" Año 16, Volumen No 23 N¹, Enero - Junio 2019 - Pág. 198 - 219

URL de la Revista: http://revistacientifica.fce.unam.edu.ar/

URL del Documento: http://revistacientifica.fce.unam.edu.ar/index.php?option=com_content\&view=article\&id=492\&ltemid=101

ISSN 1668 - 8708 - Versión en Línea

E-mail: revistacientifica@fce.unam.edu.ar
} 
http://scielo.isciii.es/scielo.php?script=sci arttext\&pid=S1135-

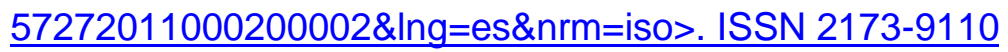

Sacks, A. A., Hernando, S. P., Aguilar, P. S., Vega, E. F. \& Fernández, R. M. (2013). Necesidades de información y uso de Internet en pacientes con cáncer de mama en España. Gaceta Sanitaria, 27(3), 241-247. Recuperado de https://www.sciencedirect.com/science/article/pii/S0213911112002348

Solves, J. J. M., Santacreu, G. L., Martínez, S. L. \& Remón, C. A. (2009). Uso de Internet por médicos de primaria y hospitales y percepción de cómo influye en su relación con los pacientes. Atención Primaria, 41(6), 308-314. Recuperado de https://www.sciencedirect.com/science/article/pii/S0212656708000528

Spinelli, E. (2004). Los modelos de comunicación. Madrid, España: Infoamérica. Recuperado de https://www.infoamerica.org/documentos pdf/spinelli01.pdf

Villaescusa Martínez, V. \& Sáez Villar, L. (2013). Búsqueda de información sobre salud a través de internet. Enfermería Global, 12(31), 197-205. Recuperado de http://scielo.isciii.es/scielo.php?script=sci arttext\&pid=S1695-

$\underline{61412013000300012 \& \operatorname{lng}=e s \& t \operatorname{lng}=e s}$

\section{RESUMEN BIOGRÁFICO}

\section{Alicia Inés Zanfrillo}

Doctora en Tecnología Educativa: Aprendizaje Virtual y Gestión del Conocimiento por la Universitat de les Illes Balears y Rovira i Virgili. Profesora Adjunta de la Facultad de Ciencias Económicas y Sociales de la Universidad Nacional de Mar del Plata orientada a investigaciones sobre TIC y vinculación

Universidad

Entorno.

\section{María Antonia Artola}

Magister en Administración de Negocios por la Universidad Nacional de Mar del Plata. Profesora Adjunta de la Facultad de Ciencias Económicas y Sociales de la Universidad Nacional de Mar del Plata en Matemática Financiera orientada a investigaciones sobre TIC y gestión de la incertidumbre.

\footnotetext{
"Visión de Futuro" Año 16, Volumen N²3 N¹, Enero - Junio 2019 - Pág. 198 - 219

URL de la Revista: http://revistacientifica.fce.unam.edu.ar/

URL del Documento: http://revistacientifica.fce.unam.edu.ar/index.php?option=com content\&view=article\&id=492\&ltemid=101

ISSN 1668 - 8708 - Versión en Línea

E-mail: revistacientifica@fce.unam.edu.ar
} 